\title{
EGFR L861Q Mutation in a Metastatic Solid-pseudopapillary Neoplasm of the Pancreas
}

\author{
KEVIN G. NEILL ${ }^{1}$, JAMES SALLER ${ }^{1}$, SAMEER AL DIFFALHA ${ }^{1}$, BARBARA A. CENTENO ${ }^{1,2}$, \\ MOKENGE P. MALAFA ${ }^{3}$ and DOMENICO COPPOLA ${ }^{1,2,4,5}$ \\ Departments of ${ }^{1}$ Anatomic Pathology, ${ }^{2}$ Chemical Biology and Molecular Medicine, \\ ${ }^{3}$ Gastrointestinal Oncology and ${ }^{4}$ Tumor Biology, \\ H. Lee Moffitt Cancer Center and Research Institute, Tampa, FL, U.S.A.; \\ ${ }^{5}$ Department of Oncological Sciences, University of South Florida, Tampa, FL, U.S.A.
}

\begin{abstract}
Solid-pseudopapillary neoplasm of the pancreas $(S P N)$ is a rare neoplasm that is typically indolent in nature. Surgical resection is the preferred method of treatment and often associated with a good prognosis. Local invasion and metastasis have been reported in a small subset of patients. Currently, there are limited data on the molecular mutation profile of invasive and metastatic SPN. In this report, we present the case of a 38-year-old female with a locallyinvasive and unresectable SPN that, despite exhaustive chemoradiotherapy, progressed to liver metastasis. Pyrosequencing of the primary pancreatic tumor antecedent to metastasis showed an uncommon EGFR mutation at L861Q in the kinase domain of exon 21. This finding, if confirmed in additional cases of metastatic SPN, would support preoperative testing for EGFR mutation analysis to detect aggressive SPNs.
\end{abstract}

Solid-pseudopapillary neoplasm (SPN) is a rare tumor of the pancreas that accounts for $2 \%$ of exocrine pancreatic tumors and $5 \%$ of cystic pancreatic tumors (1). The majority of SPNs have an indolent clinical course with $31.7 \%$ of patients asymptomatic prior to diagnosis (2). SPN can be diagnosed prior to surgical intervention using ultrasound, CT, MRI and $\mathrm{PET} / \mathrm{CT}$. The rate of diagnosis using imaging alone has been reported to be approximately $23.7 \%$ (2). Surgical resection is the preferred treatment of SPN and is predominantly curative.

This article is freely accessible online.

Correspondence to: Domenico Coppola, MD, 12902 USF Magnolia Drive, Tampa, FL 33612, U.S.A. Tel: +1 8137453275, Fax: +1 8136321708, e-mail: Domenico.coppola@moffitt.org

Key Words: Solid-pseudo-papillary, neoplasm, EGFR, L861Q, pancreas.
Approximately $10-15 \%$ of SPN are invasive (1). Tumor invasiveness can range from involvement of the surrounding organs and vascular structures to distant metastasis (3). Multiple studies have reported rare cases of SPNs with liver metastasis. In one study of 187 SPNs, only 4 were found to have metastasis to the liver. All four patients were female and had an age range of 20-72 years. Each patient with metastases underwent surgical resection with good postoperative recovery (4). In unresectable patients with evidence of local advancement or metastasis, neoadjuvant therapy has been shown to reduce symptoms, lower tumor burden and improve quality of life.

The mechanism causing malignant behavior in SPNs is currently unknown. Yeh et al. reported that three malignant SPNs displayed membranous ezrin expression (5). Ezrin is a cytoskeletal cross-linking protein. It is suggested that ezrin acts as an enhancer in the epidermal growth factor receptor (EGFR) pathway. Inhibition of erzin resulted in reduced levels of EGFR expression (5). Another study involving 10 cases of SPN (benign, $n=8$ and malignant, $n=2$ ) showed that seven of the SPN tumors showed strong expression of epidermal growth factor (EGF). In contrast, all 10 of the cases had weak or no EGFR expression, irrespective of the tumor's behavior or EGF expression (6). This may explain the less malignant potential of SPN compared with other pancreatic cystic neoplasms and invasive ductal carcinoma (6). Due to the limited amount of cases reported in the literature, it is difficult to draw a final conclusion on EGF, EGFR expression and EGFR somatic mutations in malignant SPNs.

L861Q is found on exon 21 of the EGFR tyrosine kinase domain. L861Q is an uncommon EGFR somatic mutation that has been shown to occur in $2 \%$ of lung adenocarcinomas with EGFR mutations (7). L861Q mutations cause sensitization to tyrosine kinase inhibitors (TKI), such as gefitinib and erlotinib. Patients with sensitizing EGFR mutations have been shown to respond significantly better to TKI therapy and had a significantly longer progression free survival than those with 

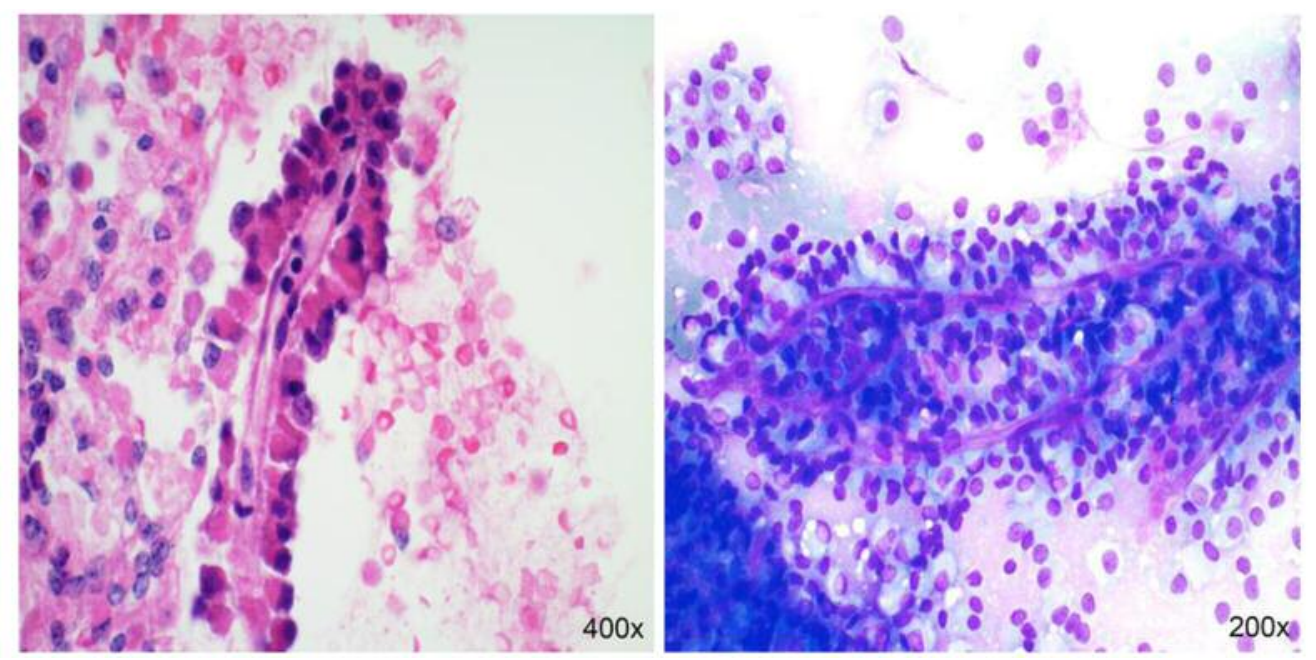

Figure 1. FNA of the mass showing tumor cells lining a hyalinized fibrovascular (H\&E) core and with cell sloughing (Diff-Quik).

other rare EGFR mutations (8). However, a study of 225 patients who received gefitinib demonstrated that uncommon EGFR mutations such as L861Q or G719S are not as responsive as more common mutations, such as L858R (9). To date there have been no studies on EGFR mutations and the response rate of TKI in cases of metastatic SPN. We present here the first documented case of a SPN with an L861Q mutation that may confer sensitivity to TKI therapy and produce therapeutic results in a tumor that has proven difficult to treat with conventional therapy.

\section{Case Report}

A 32-year-old female presented to her primary care physician with eight months of fatigue and 20-pound weight loss. On physical examination she was found to have a large palpable abdominal mass. A CT scan confirmed the presence of a $19 \times 15 \mathrm{~cm}$ abdominal neoplasm. CT-guided biopsy with cytology touch preps, which included immunohistochemistry for beta-catenin showing nuclear expression, confirmed the diagnosis of SPN of the pancreas (Figures 1 and 2B). The follow-up endoscopic ultrasound showed that the tumor had multiple vascular collaterals surrounding it. PET scan revealed intense hypermetabolic activity within the tumor with an SUV max of 27.9. A high-resolution CT scan of the pancreas showed compression of the inferior vena cava, the superior mesenteric artery and the left renal vein with mass effect on the portal vein and the duodenum. In addition, there were signs of impending gastric outlet obstruction. The patient was scheduled to have an exploratory laparotomy and a Roux-enY gastrojejunostomy. During the procedure, the SPN was found to encase the middle colic vein and superior mesenteric artery, preventing resection. The postoperative recovery from the gastrojejunostomy was complicated due to the patient developing massive hematemesis caused by GI bleeding. Approximately 19 units of packed red blood cells had been transfused in order to stabilize her condition. The patient subsequently developed aspiration and respiratory failure. She was intubated and placed on a ventilator. The GI bleeding was controlled by the performance of a selective arterial embolization of a branch of the gastroduodenal artery by interventional radiology. The patient recovered and was started on gemcitabine cisplatin. She completed 34 subsequent courses. Follow-up imaging studies confirmed that tumor had reduced in size to $11.6 \times 10.1 \mathrm{~cm}$ and developed central necrosis. A second exploratory surgery was performed and despite tumor shrinkage, the superior mesenteric vessels were still encased by the tumor. The patient received 54 Gy and resumed maintenance with gemcitabine and Avastin. A followup CT scan identified the presence of liver metastasis. The patient was started on FOLFOX and despite chemotherapy, multiple rounds of microwave ablation and transarterial chemoembolization, continues to have multiple persistent liver lesions to the present day (Figure 2A).

A formalin-fixed paraffin embedded tumor sample antecedent to metastasis and the initiation of chemoradiation was submitted for Pyrosequencing mutational analysis for EGFR, KRAS, NRAS, PIK3CA and BRAF using the QIAGEN PyroMark Q96 MD (performed at the H. Lee Moffitt Cancer Center and Research Institute). An EGFR L861Q mutation was the only mutation identified. There was a visible nucleotide base substitution of adenine for thymine, resulting in a missense mutation resulting in glutamine, instead of leucine at position 861 within exon 21 of EGFR (Figure 3). 

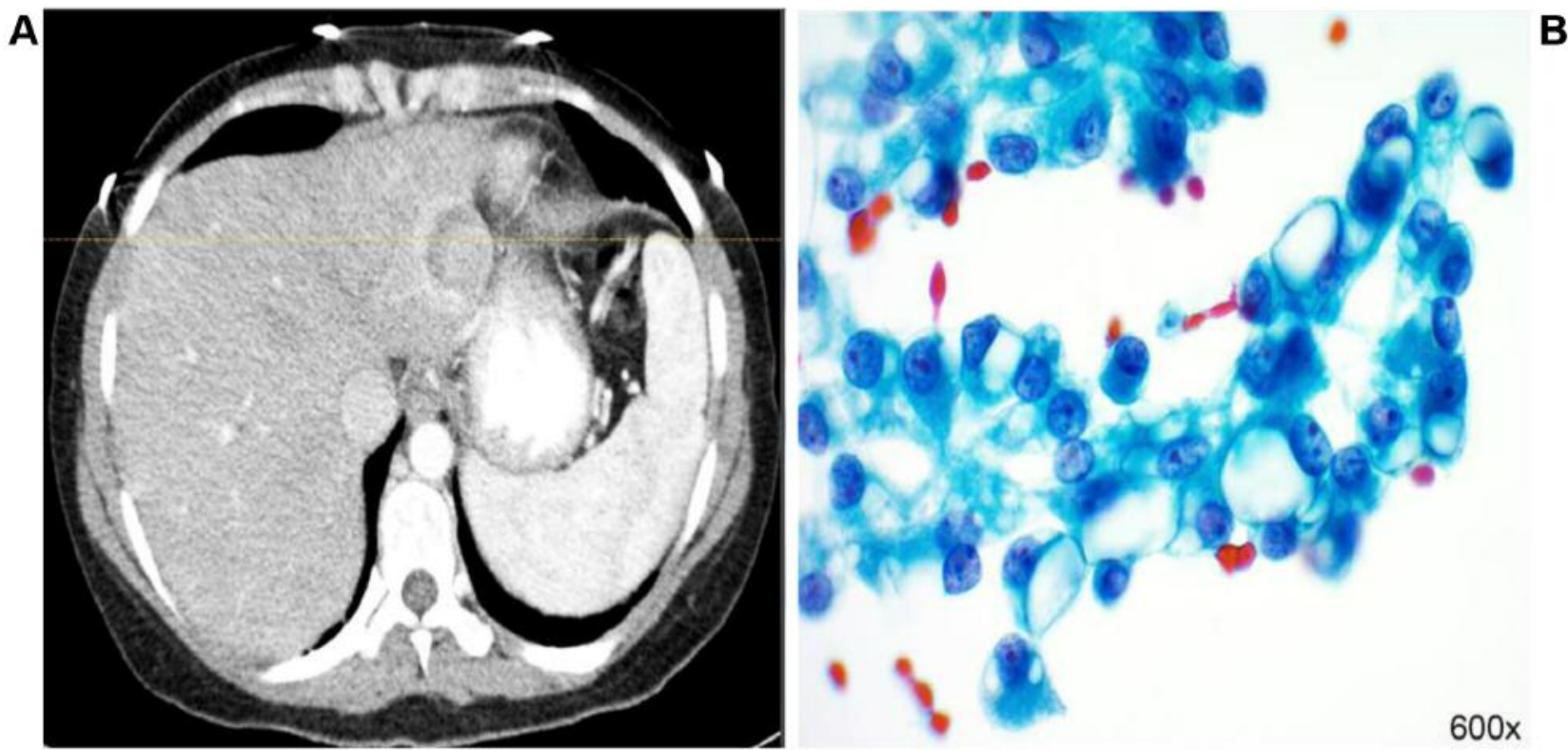

Figure 2. After therapy a CT scan confirmed multiple persistent liver metastases (A), confirmed by FNA showing cells with pseudo-papillary arrangements, cytoplasmic vacuoles and nuclear grooves $(B)$.

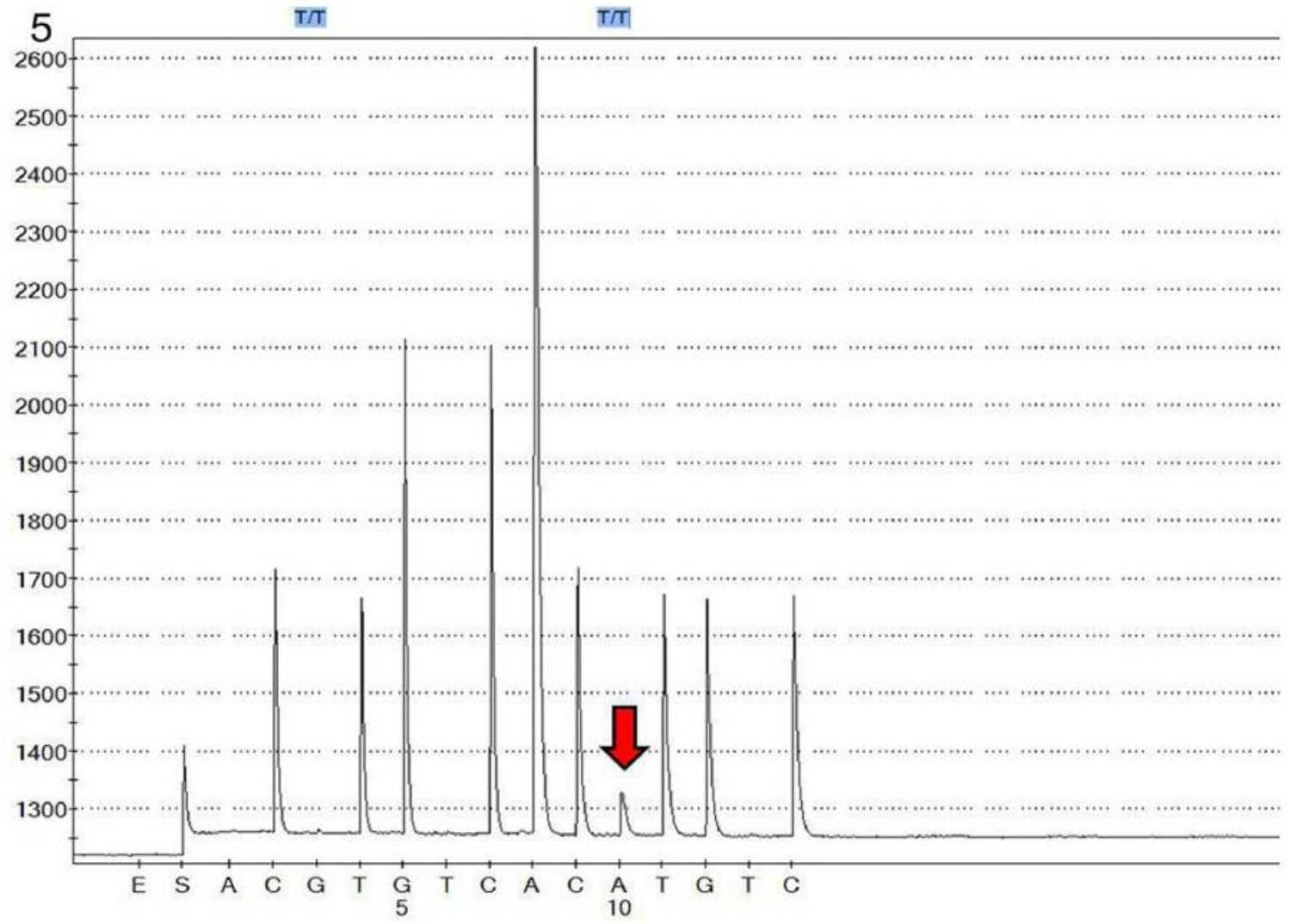

Figure 3. Pyrosequencing of the pre-treatment/pre-metastatic aggressive SPN showing a mutation (substitution) at position 861 , from (CTG) to $(C A G)$. 
This mutation was found by Pyrosequencing mutational analysis of a second SPN that did not metastasize. This result was confirmed after the biopsy tissue was retested for EGFR mutations. Additional mutation analysis could not be performed with next generation sequencing (NGS) due to an insufficient quantity of remaining pre-therapeutic tissue.

\section{Discussion}

We report on a case of a metastatic SPN with an EGFR L861Q mutation that has not been previously described in the English literature.

Metastatic SPNs constitute a very rare subclass of patients. The tumor biology behind the aggressive behavior, chemotherapy resistance and metastasis of SPN is presently unknown. This lack of information can be primarily attributed to the scarcity of cases available for molecular studies. Of the limited literature that is available, whole exome sequencing of SPN has revealed a strong association with activating mutations in between codons 32 and 37 of CTNNB1. There have been reports of other aberrations within the Wnt pathway leading to SPN, such as two cases of SPN caused by germline APC mutations have been reported in patients with Familial Adenomatous Polyposis (FAP). Furthermore through analysis of mRNA and miRNA expression, 1686 differentially expressed genes were observed in 14 SPNs compared to normal pancreatic parenchyma; which upregulated the Wnt, NOTCH, Hedgehog (HH) pathway, androgen-receptor (AR) pathways as well as epithelial mesenchymal transition (10-13).

While this is the first report of a EGFR L861Q mutation in a metastatic SPN, this type of EGFR mutation has been reported in other tumor types, predominantly found in pulmonary tumors and most commonly in Non-Small Cell Lung Cancer (NSCLC) (per cBioPortal, accessed May 10, 2017) (14, 15). Uncommon EGFR mutations make up approximately $10 \%$ of all EGFR mutations in NSCLC, the most common of which includes L861Q (2\%) (16). A study of 194 patients with lung adenocarcinoma has also shown an association between EGFR L861Q and smoking status $(7,17)$. A case report of a patient with EGFR L861Q-mutated NSCLC reported concomitant increased gene copy numbers of ALK, MET, and ROS1 (18). EGFR L861Q has also been reported as the most frequent mutation $(25 \%)$ found in a study of 20 patients with pulmonary mucoepidermoid carcinoma (19).

In NSCLC, the presence of EGFR L861Q is believed to represent a potential biomarker for sensitivity to EGFR inhibitors (20). Preclinical in vitro studies in cell lines have described EGFR L861Q mutations possessing an oncogenic activity similar to that of the EGFR L858R mutation, and possibly having sensitivity to afatinib or osimertinib (21). A study evaluating treatment of EGFR L861Q-mutated NSCLC with afatinib had demonstrated an objective response rate of $56.3 \%$ and a median progression free survival of 8.2 months (22). These data may suggest investigation using EGFR inhibitors on other EGFR L861Q-mutated tumors, including aggressive SPNs.

An analysis of the Clinical Genomics Action Committee (CGAC) database at the Moffitt Cancer Center, revealed that out of 2,306 patients with multiple tumor types having associated comprehensive genomic profiling , 3 patients $(0.13 \%)$ had EGFR L861Q mutations (2 patients that were former smokers with lung adenocarcinoma and 1 patient with GBM) (23).

In conclusion, we report a rare mutation associated with a rare cancer type. As NGS assays become more inexpensive and more widely available, a larger number of aggressive SPN will undergo comprehensive genomic profiling. NGS testing may reveal a gene mutation pattern that will lay the foundation for a standardized treatment plan for these difficult and surprisingly resilient neoplasms.

\section{References}

1 Sperti C, Berselli M, Pasquali C, Pastorelli D and Pedrazzoli S: Aggressive behaviour of solid-pseudopapillary tumor of the pancreas in adults: a case report and review of the literature. World J Gastroenterol 14: 960-965, 2008.

2 Ye J, Ma M, Cheng D, Yuan F, Deng X, Zhan Q, Shen B and Peng C: Solid-pseudopapillary tumor of the pancreas: clinical features, pathological characteristics, and origin. J Surgi Oncol 106: 728-735, 2012.

3 Honore C, Goere D, Dartigues P, Burtin P, Dumont F and Elias D: Peritoneal carcinomatosis from solid pseudopapillary neoplasm (Frantz's tumour) of the pancreas treated with HIPEC. Anticancer Res 32: 1069-1073, 2012.

4 Wang WB, Zhang TP, Sun MQ, Peng Z, Chen G and Zhao YP: Solid pseudopapillary tumor of the pancreas with liver metastasis: Clinical features and management. Eur J Surg Oncol 40: 1572-1577, 2014.

5 Yeh TS, Tseng JH, Liu NJ, Chen TC, Jan YY and Chen MF: Significance of cellular distribution of ezrin in pancreatic cystic neoplasms and ductal adenocarcinoma. Arch Surg 140: 11841190, 2005

6 Yeh TS, Jan YY, Chiu CT, Ho YB, Chen TC, Lee KF, Chan KM, Hsu JC, Hwang TL and Chen MF: Characterisation of oestrogen receptor, progesterone receptor, trefoil factor 1 , and epidermal growth factor and its receptor in pancreatic cystic neoplasms and pancreatic ductal adenocarcinoma. Gut 51: 712716, 2002.

7 Mitsudomi T and Yatabe Y: Epidermal growth factor receptor in relation to tumor development: EGFR gene and cancer. FEBS J 277: 301-308, 2010.

8 Lohinai Z, Hoda MA, Fabian K, Ostoros G, Raso E, Barbai T, Timar J, Kovalszky I, Cserepes M, Rozsas A, Laszlo V, Grusch M, Berger W, Klepetko W, Moldvay J, Dome B and Hegedus B: Distinct epidemiology and clinical consequence of classic versus rare EGFR mutations in lung adenocarcinoma. J Thorac Oncol 10: 738-746, 2015.

9 Watanabe S, Minegishi Y, Yoshizawa H, Maemondo M, Inoue A, Sugawara S, Isobe H, Harada M, Ishii Y, Gemma A, Hagiwara K and Kobayashi K: Effectiveness of gefitinib against non-small-cell lung cancer with the uncommon EGFR mutations G719X and L861Q. J Thorac Oncol 9: 189-194, 2014. 
10 Hackeng WM, Hruban RH, Offerhaus GJ and Brosens LA: Surgical and molecular pathology of pancreatic neoplasms. Diagn Pathol 11: 47, 2016.

11 Park M, Lim JS, Lee HJ, Na K, Lee MJ, Kang CM, Paik YK and Kim H: Distinct protein expression profiles of solidpseudopapillary neoplasms of the pancreas. J Proteome Res 14: 3007-3014, 2015.

12 Park M, Kim M, Hwang D, Park M, Kim WK, Kim SK, Shin J, Park ES, Kang CM, Paik YK and Kim H: Characterization of gene expression and activated signaling pathways in solidpseudopapillary neoplasm of pancreas. Mod Pathol 27: 580-593, 2014.

13 Cavard C, Audebourg A, Letourneur F, Audard V, Beuvon F, Cagnard N, Radenen B, Varlet P, Vacher-Lavenu MC, Perret C and Terris B: Gene expression profiling provides insights into the pathways involved in solid pseudopapillary neoplasm of the pancreas. J Pathol 218: 201-209, 2009.

14 Gao J, Aksoy BA, Dogrusoz U, Dresdner G, Gross B, Sumer SO, Sun Y, Jacobsen A, Sinha R, Larsson E, Cerami E, Sander $\mathrm{C}$ and Schultz $\mathrm{N}$ : Integrative analysis of complex cancer genomics and clinical profiles using the cBioPortal. Sci Signal 6: pl1, 2013

15 Cerami E, Gao J, Dogrusoz U, Gross BE, Sumer SO, Aksoy BA, Jacobsen A, Byrne CJ, Heuer ML, Larsson E, Antipin Y, Reva B, Goldberg AP, Sander C and Schultz N: The cBio cancer genomics portal: an open platform for exploring multidimensional cancer genomics data. Cancer Discov 2: 401-404, 2012.

$16 \mathrm{Wu}$ TH, Hsiue EH, Lee JH, Lin CC and Yang JC: New data on clinical decisions in NSCLC patients with uncommon EGFR mutations. Expert Rev Respir Med 11: 51-55, 2017.

17 Wang Q, Mou J, Yang X, He Y, Li Z, Luo Q, Li Y, Lin L, Ma Y and Xiao $\mathrm{H}$ : EGFR mutations in patients with lung adenocarcinoma in southwest China: are G719S/A and L861Q more likely detected in tumors derived from smokers? Lung Cancer (Auckland, NZ) 4: 27-33, 2013.

18 Pilotto S, Bria E, Peretti U, Massari F, Garassino M, Pelosi G and Tortora G: Lung adenocarcinoma patient refractory to gefitinib and responsive to crizotinib, with concurrent rare mutation of the epidermal growth factor receptor (L861Q) and increased ALK/MET/ROS1 gene copy number. J Thorac Oncol 8: e105-106, 2013.
19 Yu Y, Song Z, Gao H, Zhu L, Lu S, Zhang J and Luo Q: EGFR L861Q mutation is a frequent feature of pulmonary mucoepidermoid carcinoma. J Cancer Res Clin Oncol 138: 1421-1425, 2012.

20. Otsuka T, Mori M, Yano Y, Uchida J, Nishino K, Kaji R, Hata A, Hattori Y, Urata Y, Kaneda T, Tachihara M, Imamura F, Katakami N, Negoro S, Morita S and Yokota S: Effectiveness of tyrosine kinase inhibitors in Japanese patients with non-small cell lung cancer harboring minor epidermal growth factor receptor mutations: Results from a multicenter retrospective study (HANSHIN Oncology Group 0212). Anticancer Res 35: 3885-3891, 2015.

21 Banno E, Togashi Y, Nakamura Y, Chiba M, Kobayashi Y, Hayashi H, Terashima M, de Velasco MA, Sakai K, Fujita Y, Mitsudomi T and Nishio K: Sensitivities to various epidermal growth factor receptor-tyrosine kinase inhibitors of uncommon epidermal growth factor receptor mutations L861Q and S768I: What is the optimal epidermal growth factor receptor-tyrosine kinase inhibitor? Cancer Sci 107: 1134-1140, 2016.

22 Yang JC, Sequist LV, Geater SL, Tsai CM, Mok TS, Schuler M, Yamamoto N, Yu CJ, Ou SH, Zhou C, Massey D, Zazulina V and $\mathrm{Wu}$ YL: Clinical activity of afatinib in patients with advanced non-small-cell lung cancer harbouring uncommon EGFR mutations: a combined post-hoc analysis of LUX-Lung 2, LUX-Lung 3, and LUX-Lung 6. Lancet Oncol 16: 830-838, 2015.

23 Vela CM, Knepper TC, Gillis NK, Walko CM, McLeod HL and Hicks JK: Quantitation of targetable somatic mutations among patients evaluated by a personalized medicine clinical service: Considerations for off-label drug use. Pharmacotherapy 9: 1043$1051,2017$.

Received December 12, 2017

Revised February 20, 2018

Accepted March 9, 2018 